\title{
LXXVIII. On the decomposition of metallic salts by the magnet
}

\section{Mr.J. Murray}

To cite this article: Mr. J. Murray (1821) LXXVIII. On the decomposition of metallic salts by the magnet, Philosophical Magazine Series 1, 58:283, 380-382, DOI: $10.1080 / 14786442108652643$

To link to this article: http://dx.doi.org/10.1080/14786442108652643

曲 Published online: 27 Jul 2009.

Submit your article to this journal $\pi$

Џ Article views: 3

Q View related articles $\sqsubset$ 
near it of the third class. Five more in view, differently dispersed ahout the quintuple.

$\boldsymbol{P}$. V. 300.) This star was obs. by Piazzi when looking for 231 of Mayer, which he could not find.

$64 \chi .4$ Orionis.) Fl. R. A. requires -45 '. Bode calls this $\chi$. 3 . $62 \times .3$ Orionis.) Bode calls this $x .4$.

$P$. V. 328.) The place of Bode's 256 Orionis does not agree very well with this, the $R$. A. being $+2^{\prime} 5 l^{\prime \prime}:$ Decl. $+41^{\prime \prime}$.

$M$. 234.) Mayer's position is derived from an imperfect observation.

4 Geminorum.) Mayer's R. A requires $-17^{\prime \prime} \cdot 4$. Decl. $-12^{\prime \prime} \cdot 3$; it was obs. by him but once.

Anon. R. A. $\left.89^{\circ} 4 l^{\prime}\right)$ Hist. Cél. p. 262. Double. Hers.VI. 114. “s About $\frac{r}{2}$ degree s. preceding 69 Orionis, nearly towards $\lambda_{\text {, }}$ Considerably unequal. L. p. $r$; S. d. Distance $90^{\prime \prime} \cdot 63$. Pos. 22. 1 s. following."

*** With reference to what is stated at page 127 of the present volume, it may be proper to mention, that the Zodiacal Stars of Wollaston's Catalogue, which are omitted in this, consist of such as are not now to be seen in the heavens, and which there is good reason to suppose never to have existed, but to have been inserted in the original catalogues through miscalculation. The list of such stars is deferred until the completion of the present Catalogue.

P.S. The compiler takes the liberty of mentioning, that should any person be in possession of unpublished materials which may serve to enrich this Zodiacal Catalogue, although not of sufficient importance for separate publication; he shall be happy to avail himself of them, on their being communicated through the Editor.

LXXVIII. On the Decomposition of Metallic Salts ly the Magnet. By Mr. J. Murray.

IN my Paper "on the decomposition of metallic salts by the magnet" transmitted to the Royal Society of Edinburgh I referred to experiments which seemed to me unequivocally to prove the influence of magnetism in the decomposition of metallic salts -I continue to receive renewed evidence of the truth of my conelusions - I shall here take leave to select a few of the numerous experiments repeated in the course of my researches, and it would, methinks, be difficult to summon any objection to them; 1 confess that they appear to me quite satisfactory.

A solution of permuriate of mercury was by the magnet soon reduced into running or metallic mercury, and the supernatant fluid was not affected by the albumen of the egg. 
Hence, fine steel filings magnetized and administered in sirup will be an admirable antidote to corrosive sublimate.

Nitromuriate of platinum was decomposed with a brisk effervescence distinctly audible and with a visible spray between the eye and light.

Fine Dutch steel wire was selected, and proved to be non-magnetic.-It was thrown into nitrate of silver where it remained for 14 hours without being affected, part of this was made the uniting wire between the $N$. and $S$. poles of 2 bar magnets; when, it became speedily plumed with crystals of silver.

A portion of the same wire was snapped in twain and the magnet passed over one of the fragments and both projected into solution of nitrate of silver-that which was magnetised reduced the sifver, while the other remained inert.

The magnetic bar was coated with copal varnish and placed into solution of muriate of mercury, but reduction took place as if no such film had interposed.

Two magnetic bars were left for 2 days in phosporous acid. The acid was decomposed-the north pole of one of the bars was scarcely affected, but the sointh pole of the other was corroded $\frac{1}{8}$ inch deep, and developed the fasciculated structure described by Mr. Daniel.

The two magnetic poles (N. and S.) of two har magnets immersed in nitrate of silver were united about $\frac{I}{2}$ inch from their extremities by a thread of steel; a precipitation of erystals of reduced silver took place about the uniting wire (very few below) and the uniting wire itself became so invested.

I have succeeded in decomposing every metallic salt in this way to which $I$ have applied the magnet; and I have yet to be informed that steel, simply as a carburet of iron, will attract all acids whatever from every metal whatsoever.

A portion of platinum wire that suffered no change in nitrate of silver, in solution, was made the uniting wire between the poles of a powerful horse-shoe magnet (that supported 12lbs. weight). When this was immersed into nitrate of silver it soon became discoloured and acted upon.

W'hen a magnetic bar is plunged into solution of nitrate of silver it accomplishes its complete reduction, however considerable the quantity, the surface of the magnet in contact with the solution is not abraded, but the surface above the solution is much corroded from the escape of the acid vapour, the consequence of decomposition.

When in the nitrate of silver the N. pole hecame instantly itudded with brilliant pallets of silver, and formed more rapidly and more copiously round it than round the south pole. These crystalline 
crystalline pallets exhibited evident polarity, and were affected by the approach of a fine steel plate.

When the magnet is plunged into a solution of muriate of mercury, and the decomposition takes place which yields globules of fluid metallic mercury, it will be seen that the action is most intense at the angles and base of the bar, and the reduction there more copious and prompt. 'This phenomenon is manifested when a magnetic bar is rolled in iron filings; for it will then be perceived that the quantity of adhering particles is much greater in these places than in other parts of the surface.

It is an interesting spectacle to witness the reduction of minute metallic balls around the poles, particularly the north and its base, with a square floor reflecting the form or impress of the inclined bar-the reduction commerces at the edges, and is striking and beautiful.

J. Murray.

LXXIX. Notices respecting New Books.

The Imperial Almanack ; or, Annual Compendium of Astronomical, Statistical, Scientific, and Interesting Information, for the Year of our Lord 1822.

$W_{\mathbf{E}}$ conceive it to be quite within the scope of our duty as journalists of science, to notice an Almanack which comes forth with any pretensions to the character of scientific. Most of the Almanacks published in this country are sad indications of the ignorance which still prevails among our peasantry, ignorance which can find gratification in the perusal of astrological predictions, and which can tremble or rejoice in the expectation of events pretended to depend upon the inutual aspects of the moon and planets. Among the Almanacks published by the Stationers' Company, there are a few exceptions to this censure; especially those widely-circulated productions the Ladies' Diary, the Gentleman's Diary, and White's Ephemeris s the latter of which, we are glad to observe, has lately received some valuable improvements.

The Imperial Almanack, to whose first number we now beg leave to draw the attention of our readers; presents several nev and interesting features. The calendar part, which occupiss 24 pages, two to each month, exhibits all the usual matter of an Almanack, such as the lunations, the anniversaries, holidays, \&ic the times of rising and setting of the sun and moon, and of the moon's southing; contains also, a column for the sun's rigit ascension and declination; and comprises, instead of the ustal column entitled " equation of time," one that shows the man 